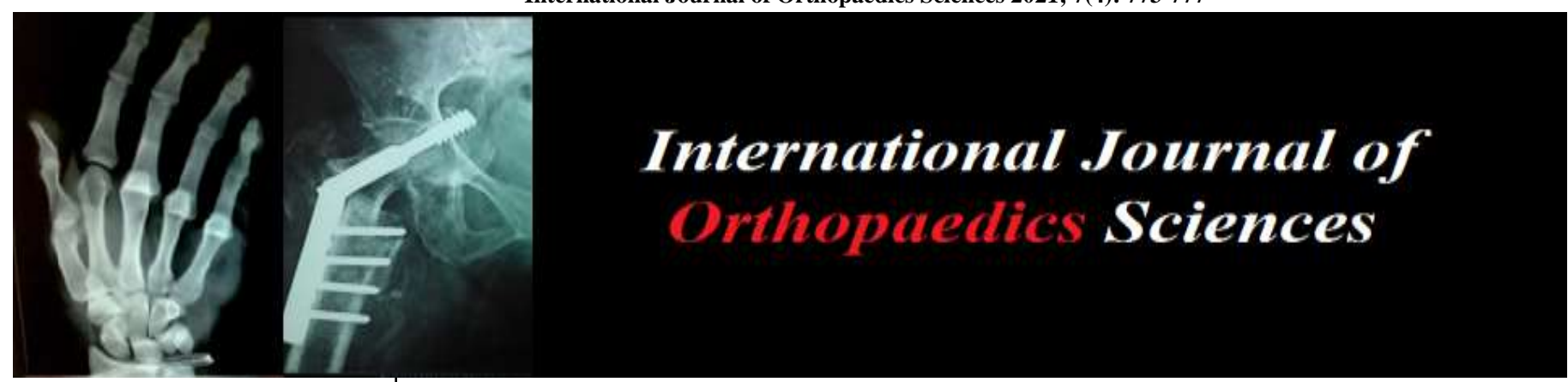

E-ISSN: 2395-1958

P-ISSN: 2706-6630

IJOS 2021; 7(4): 773-777

(C) 2021 IJOS

www.orthopaper.com

Received: 23-06-2021

Accepted: 25-07-2021

\section{Dr. Abilash}

Assistant Professor,

Department of Orthopaedics,

Sri Lakshmi Narayana Institute

of Medical Sciences, Pondicherry

India

\section{Dr. Sarath Kumar}

Post Graduate Resident,

Department of Orthopaedics,

Sri Lakshmi Narayana Institute

of Medical Sciences,

Pondicherry, India

\section{Non-union of medial malleolar fractures}

\section{Dr. Abilash and Dr. Sarath Kumar}

DOI: https://doi.org/10.22271/ortho.2021.v7.i4k.2968

\section{Abstract}

Aim: To assess the functional and radiological outcome of Nonunion medial mallolar fractures treated surgically with cc screw fixation and bone grafting.

Materials and Methods: A prospective type of study conducted in our institute with 23 patients, 15 male and 8 female from august 2019 to September 2021. patients who has no signs of union radoilogically with severe disabling symptoms that affects their day to day activities with history of trauma to the ankle before 3 months were assessed clinically and confirmed radiologically as medial malleolar nonunion and were treated surgically with corticocancellous screw fixation and bone grafting postoperatively patients were regularly assessed clinical as well as radiologically outcome was measured using AOFAS and OMAS scoring.

Results: Out of 23 patients who were taken up for final study 18 patients got excellent results, 3 patients with good and 2 patients with fair outcome. AOFAS score of 96.53 and OMAS score of 94.86

Conclusion: We conclude from our study that good functional outcome can be obtained for medial malleolus nonunion treated by open reduction with corticocancellous screw fixation and bone grafting followed by regular postoperative follow up and physical therapy.

Keywords: Medial malleolar, cc screw fixation and bone grafting, union radoilogically

\section{Introduction}

Isolated medial malleolus fracture accounts for about only $7 \%$ of ankle fractures which when occurs in combination with other fracture accounts for about $20 \%{ }^{[14]}$. Eventhough Nonunion of medial malleolus fracture is rare, accounts for about 5-30\% which leads to long term complications like pain causing disabilities, instability and inflammation that needs an active intervention for a permanent relief ${ }^{[10]}$. Brian M. Capogna et al. in a study described that Nonunion is a complete arrest of the healing process following a fracture. Causes of nonunion are classified into 4 major categories ${ }^{[1]}$ excessive movement over the fracture site due to improper immobilization ${ }^{[2]}$, due to vascular insufficiency ${ }^{[3]}$, excessive gap between the fracture site and ${ }^{[4]}$ those associated with infections. In that study the author was specifying that risk factors for nonunion can be intrinsic or extrinsic. Due to lack of stability, poor reduction and blood supply or due to interposition of soft tissues which plays a major role in malleolar fractures because periosteum or surrounding tendons may get entrapped between the fracture fragments synovial lining and synovial fluid that disrupting the fracture heamatoma play a major role on non-union. Diabetes, infection, usage of tobacco, history of radiation therapy, old age, obesity are intrinsic factors that are associated with nonunion ${ }^{[15]}$. As we discussed the need for surgical intervention in cases of nonunion of medial malleolus is indicated due to unstable joint with reduced range of movements on ankle joint and disabling pain that affects the activities of daily living (ADL) which brings the patient to the hospital often.so in our study the nonunion of medial malleolus was treated surgically after appreciating no signs of union radiologically after 3 months of fracture surgical procedure was done using cancellous screw fixation with bone grafting and our aim of the study is to assess about the functional as well as radiological outcome.

\section{Materials and Methods}

We conducted the study as per the principles of Declaration of Helsinki after obtaining an informed consent from the patient by explaining the treatment modality which they undergo as well as processing of their personal data.

\section{Dr. Abilash}

Department of Orthopaedics,

Sri Lakshmi Narayana Institute

of Medical Sciences, Pondicherry,

India 
The study was conducted between august 2019 to September 2021 in our institute. Patients between age group 18 and 65 who sustained medial malleolus fracture and underwent a conservative management initially and approached our centre with symptoms like significant pain, inflammation, and instability ${ }^{[12]}$ which is affecting the activities of daily living after 3 months of fracture. Patients were assessed clinicaly and radiologicaly by Xray (through standard AP, lateral and mortice view) and MRI Scan before taken up for the study. Out of 27 patients only 23 patients were taken up for final study ( 2 patient with severe comorbidities and 2 patients loss to follow up).

Intra Operative Procedure: Regional epidural spinal anaesthesia was preferred for majority of the patients. standard medial approach is used centering the medial malleolus and the incision was curved anteriorly on its distal end. After reaching the fracture site the debris including periosteal remnants and fibrous tissue was removed and the fracture sites freshened until a fresh bleeding was appreciated. Adequate space between the fracture sites was achieved so that it can be filled with tricortical bone graft from the iliac crest. Once graft is applied the fracture site was reduced with Weber's reduction clamp. After approximating the fracture site 2-3 K wires of standard sizes were used to hold the fracture site. 2 partially threaded (To achieve a lag effect) cancellous screw measures 3.5 to $4.5 \mathrm{~mm}$ is preferred and used for fixing the fracture site under the fluoroscopy guidance.

Post operatively wound care was provided to avoid infections and implant failure. Strict non-weight bearing was initiated with below knee slab for 4 weeks to 6 weeks. Patients were adviced for regular follow up and X-rays were taken regularly to assess the fracture union depends on which partial and later total weight bearing was initiated. Patients were assessed clinically and scoring was done using AOFAS and OMAS scoring system.

\section{Results}

Patients were regularly followed up and at the end of 6 to 8 months functional and radiological improvements were assessed. The end results were collected and compiled through Microsoft excel. Among 23 patients who were included in the final study 15 were males and 8 were females. Mean age of patients during time of injury is 32 years. Both clinical and radiological assessment were found to be improved in all the patients in our study group which was graded according to AOFAS and OMAS grading system.

Table 1: Results of AOFAS and Omas Scoring System.

\begin{tabular}{|c|c|c|}
\hline Scoring system & AOFAS & OMAS \\
\hline mean \pm SD (23 Patients) & $96.53 \pm 5.55$ & $94.86 \pm 5.56$ \\
\hline
\end{tabular}

AOFAS scoring system has a maximum of 100 points which is further classified as excellent ( $\geq 90$ points), good (80-89 points), fair (70-79) and poor ( $\leq 69$ points) ${ }^{[13]}$. Post operative wound infection was found in 3 cases which was treated early and effectively with good antibiotics and found to be healed well on further follow up without any deep infections. Radiologically union of fracture site looks satisfactory with significant amount of callus and with zero cases of screw breakage or screw backout.

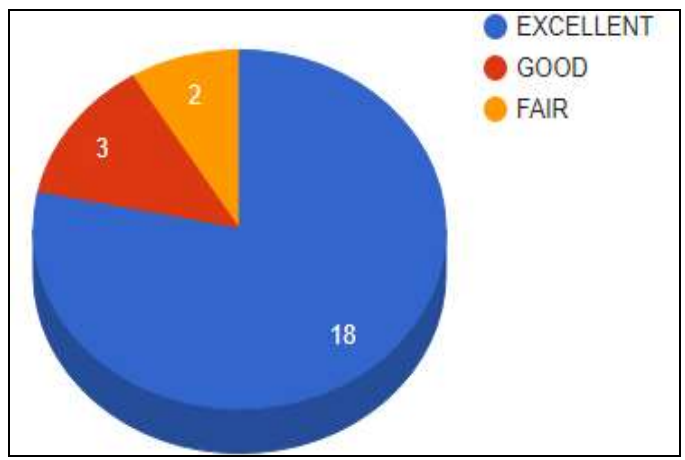

Chart 1: Outcome of AOFAS Scoring System.

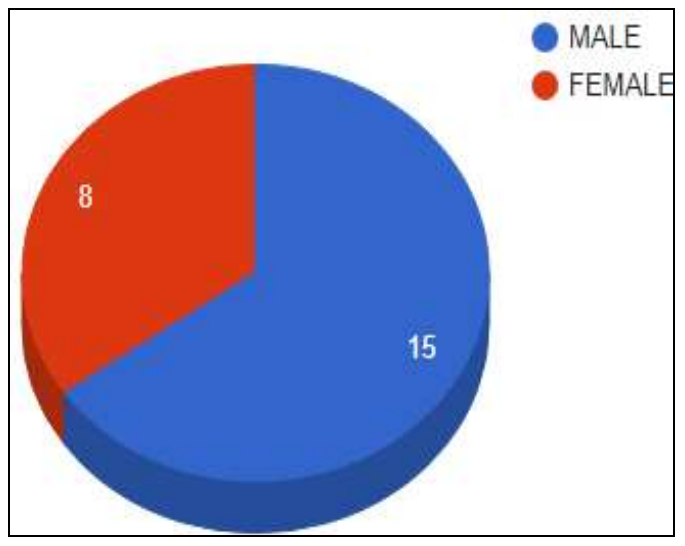

Chart 2: Sex Difference
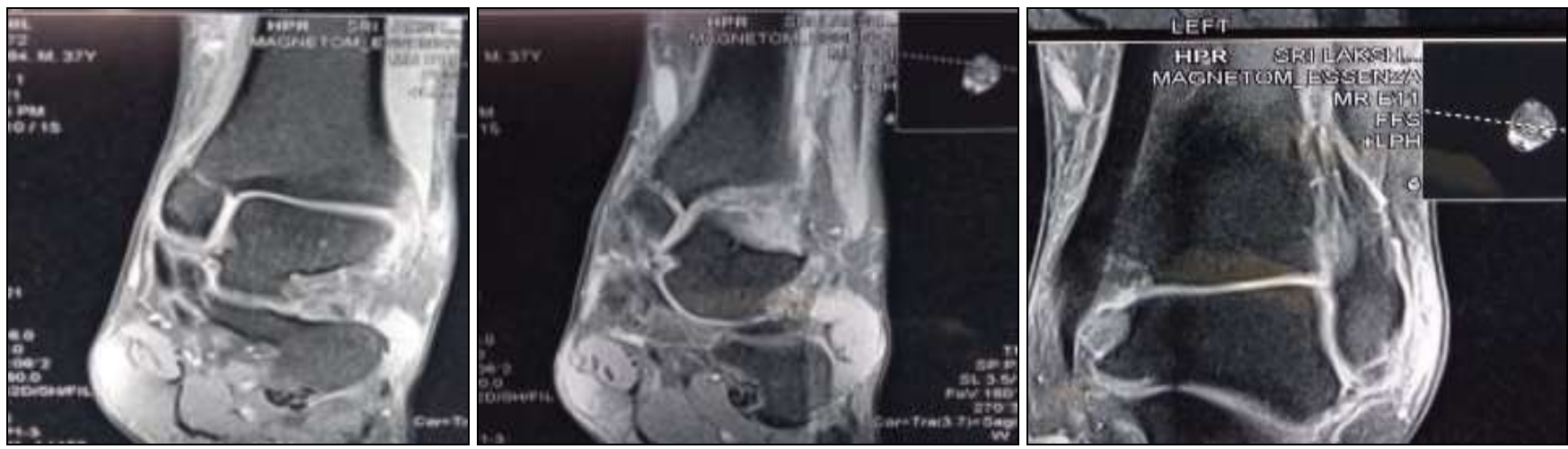

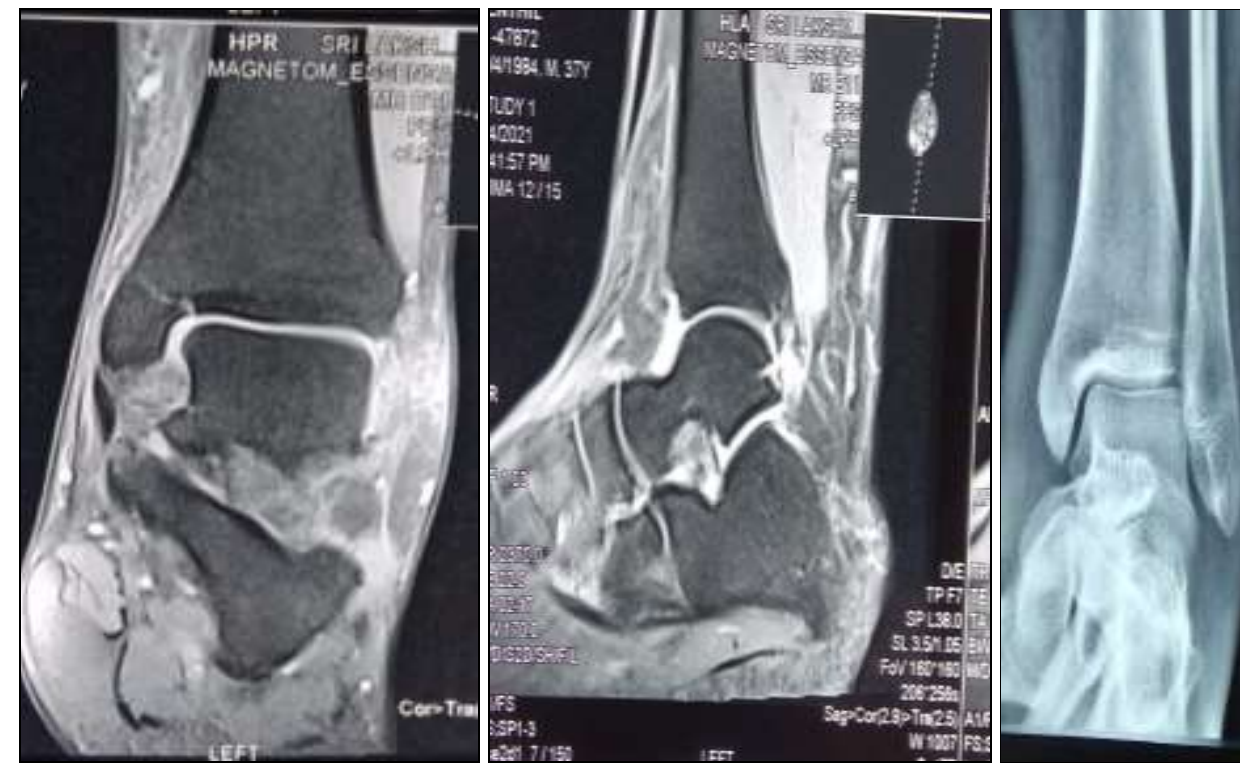

(1)

Fig 1: Images Showing Preoperative Radiological Assessment.
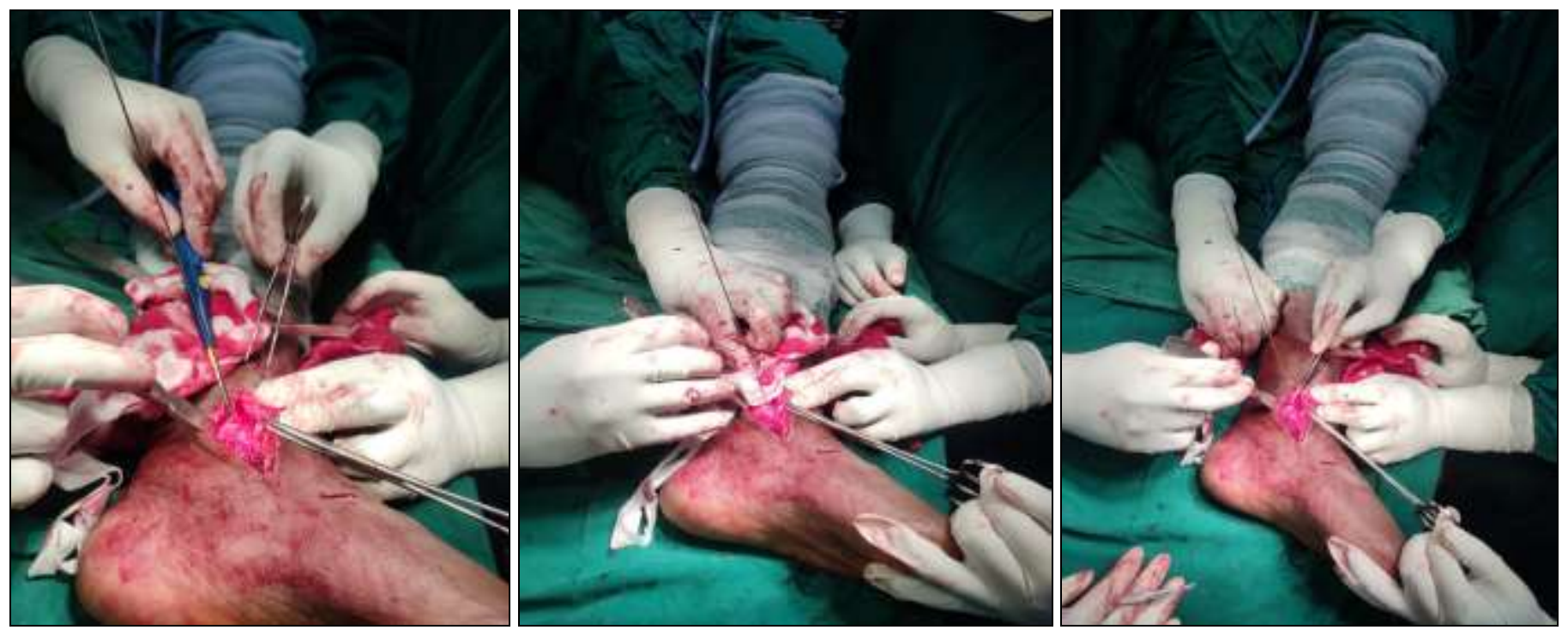

Fig 2: Images Showing Intra Operative Images

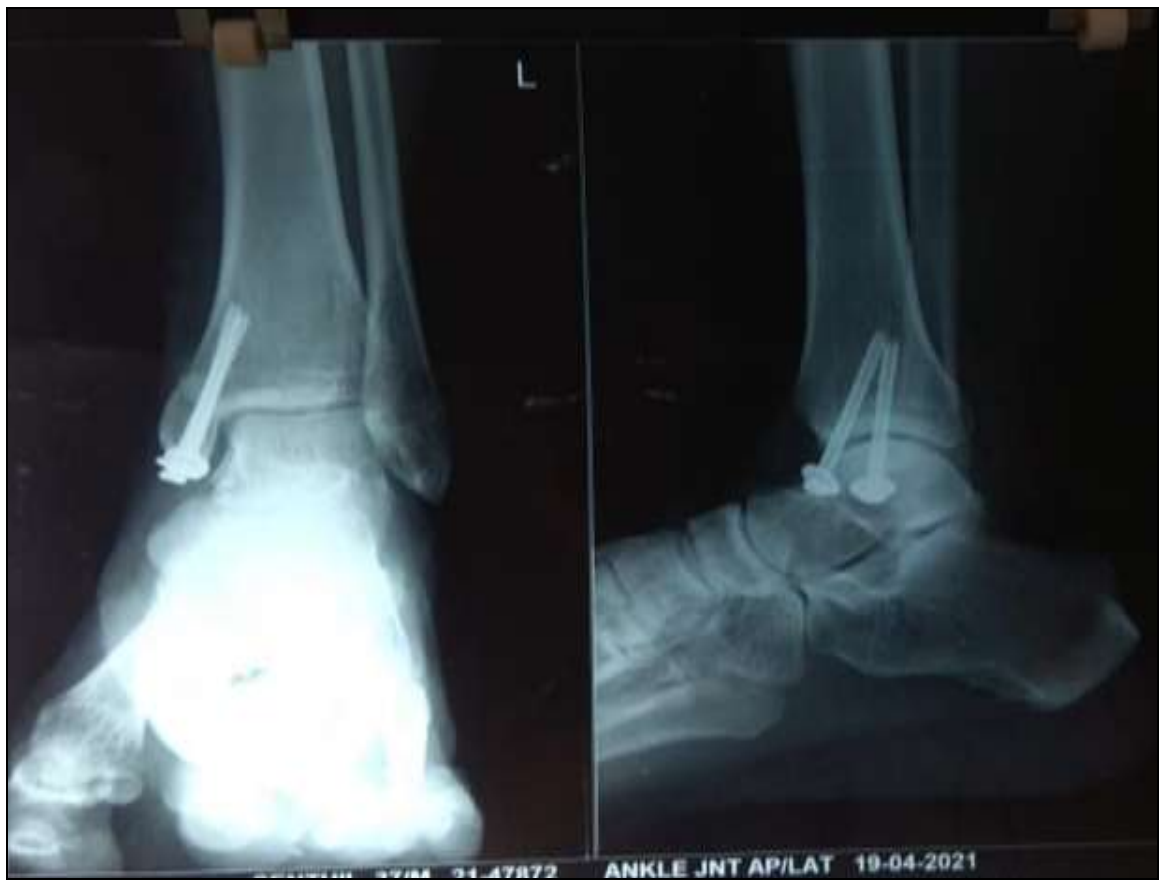

Fig 3: Image Showing Post Operative Follow Up X-Ray. 


\section{Discussion}

Due to complexity and multiplicity of the ankle joint it is challenging for many of the physicians to asses the patients with pathologies in ankle joint. Anatomical structures of ankle joint include 26 bones with 33 joints which is surrounded by many ligaments, tendons and muscles in each foot which contribute to the functioning of ankle joint ${ }^{[1,2]}$. Various classifications were involved in ankle fractures among which most commonly used are lauge-hansens and dennis weber. As per lauge hansens in S-ER (STAGE 4), S-ADD (STAGE 2), P-ER (STAGE 1), P-AB (STAGE 1) found to have medial malleolar fractures and in Dennis weber classification Type B and $\mathrm{C}$ involves medial malleolar fracture. Fangke $\mathrm{Hu}$ et al. classified medial malleolar fractures based on the 3D Reconstruction CT morphology into 4 types (type 1,2,3, and 4 ) of which type 2 is most common ${ }^{[8]}$. Herscovici et al. simplified medial malleolus fracture into four types (Type A, B, C, D) based on AP radiograph of ankle joint ${ }^{[14]}$. Paul And rzejowski, et al. in a study explained about a 'Diamond concept' which explains about the need for the availability of osteoinductive mediators, osteoconductive matrix, osteogenic cells, optimum mechanical environment, adequate vascularity, and identifying any existing comorbidities for a successful bone healing [4]. Host factors like gender,age, smoking, alcohol, smoking, etc and Biological factors like vascular supply, infection, soft tissue coverage and mechanical factors are fracture configuration, method of fixation and degree of mobilization are the factors play a role on union of fracture site [6]. Non union as per "The U.S. Food and Drug Administration defined non union as "established when a minimum of 9 months has elapsed since injury and the fracture shows no visible progressive signs of healing for 3 months". As this definition is not suitable for all the fractures Brinker defined "A fracture that, in the opinion of the treating physician, has no possibility of healing without further intervention." until clinical as well as radiographic evidence is noted we couldn't conclude as non union and the time frame for non union varies for different fracture sites ${ }^{[5]}$. Types of non union are hypertrophic nonunion (abundant callus formation), oligotrophic non union (poor callus formation) and atrophic non union with no callus formation ${ }^{[7]}$. Generally Nonunion can occur due to poor blood supply, improper reduction, instability and interposed soft tissues into the fracture site which is the most common scenario in case of medial malleolus nonunion ${ }^{[9]}$. SK Stewart et al. in his study mentioning about optimization of the mechanical environment to avoid nonunion. Excessive strain which prevents transformation from fibrous tissue to osseus tissue that leads to nonunion which can be corrected surgically or through immobilization. In a study conducted by Haluk Çabu et al. importance of epiphyseal scar joint line for finding out an optimal screw length in fixing medial malleolus was explained.in case of patients with more than 60 years of age longer screw should be avoided and shorter screws that engaged in epiphyseal scar is to be preferred i.e screw length should decrease as the age increases ${ }^{[17]}$. In a comparative study between percutaneous and open reduction and internal fixation of malleolar fractures conducted by Andrew P. Matson et al. found to have equal outcome with no advantage of one over the other ${ }^{[18]}$. A study on functional outcome of Lag Screw Fixation of Medial Malleolar Fractures conducted by William M. Ricci et al. found that Bicortical Fully Threaded Lag Screws has better outcome than Unicortical Partially threaded Lag Screws. Use of autologous bone grafting is highly recommended due to its innate capacity to recreate the biological environment of normal bone healing but with few complications like donor site morbidity ${ }^{[20]}$. In another study atrophic nonunion or cases with bone loss autogenous bone graft is suggested as the gold standard treatment. Excellent osteoinductive properties of autogenous bone graft makes it superior over allograft material. Added to that it provides osteoconductive properties without any risk of immunogenicity or risk of disease transfer ${ }^{[9]}$. From our study we found that people who are not willing for surgery, early weight bearing during conservative treatment, poor pop care, irregular follow up and due to lack of awareness who gets treated inadequately by a native bone setter has higher chances of developing nonunion. patients were diagnosed clinically and confirmed radiologically underwent open reduction internal fixation with cc screws and bone grafting and immobilized for a period of 4-6 weeks followed by physiotherapy was resulting in excellent results. References from many study shows the role of soft tissue interposition being a major factor in cases of nonunion of medial malleolus is high and play a major role on its treatment outcome.

In a study conducted by Kevin $\mathrm{J}$ et al. explained about the need for stable fixation in cases of disruption of the ankle mortice by fracture of the plafond or syndesmosis or the malleoli can lead to ankle instability and lack of articular congruity which can end up in degenerative arthritis.so to avoid those complications anatomical reduction and stable fixation of fracture around the ankle and also to restore the function and to obtain union. He also explained that nonunion of ankle can lead to stiffness of joint, gait disturbances, prolonged morbidity as well as prolonged stress on the patient. malreduced nonunion can affect adjacent knee as well as subtalar joint by affecting the mechanical axis of the limb [21]. The role of Low intensity pulsed ultrasound therapy in nonunion was studied by Kavyansh Bhan et al. and found that $78.57 \%$ of success rate were seen ${ }^{[22]}$. The need for definitive fixation of medial malleolus explained by Craig R. Lareau et $a l$. by stating a fact that on mortice view medial translation of the talus is prevented by the medial malleolus and also by anterior talofibular and posterior talofibular ligaments. Importance of medial malleolus in maintaining the normal contact area and pressure of the ankle joint throughout the complete range of motion in ankle joint is highly significant which can lead to post traumatic arthritis or instability of ankle joint in cases of medial malleolus nonunion or malunion ${ }^{[28]}$. So in our study discussed in detail about the reasons for medial malleolus nonunion and the need to provide a stable fixation to avoid complications of nonunion medial malleolus.

\section{Conclusion}

We conclude from our study that good functional outcome can be obtained for medial malleolus nonunion treated by open reduction with corticocancellous screw fixation and bone grafting followed by regular postoperative follow up and physical therapy.

\section{References}

1. Alazzawi S, Sukeik M, King D, Vemulapalli K. Foot and ankle history and clinical examination: A guide to everyday practice. World journal of orthopedics 2017;8(1):21.

2. Coughlin MJ, Saltzman CL, Anderson RB. Mann's surgery of the foot and ankle. Amsterdam: Elsevier Saunders 2014, 2186

3. Hanhisuanto S, Kortekangas T, Pakarinen H, Flinkkilä T, Leskelä HV. The functional outcome and quality of life 
after treatment of isolated medial malleolar fractures. Foot and Ankle Surgery 2017;23(4):225-9.

4. Andrzejowski P, Giannoudis PV. The 'diamond concept'for long bone non-union management. Journal of Orthopaedics and Traumatology 2019;20(1):1-3.

5. Brinker MR et al. Nonunions: evaluation and treatment. In Browner BD, Jupiter JB, Levine AM, editors:Skeletal trauma: basic science, management, and reconstruction, ed 3, Philadelphia, Saunders 2003.

6. Stewart SK. Fracture non-union: a review of clinical challenges and future research needs. Malaysian orthopaedic journal 2019;13(2):1.

7. Nicholson JA, Makaram N, Keating JF, Simpson AH. Fracture nonunion in long bones: A literature review of risk factors and surgical management. Injury 2020.

8. $\mathrm{Hu} \mathrm{F}, \mathrm{Bu} \mathrm{G}$, Liang J, Huang $\mathrm{H}$, He J. A novel classification for medial malleolar fracture based on the 3-D reconstruction CT. Journal of orthopaedic surgery and research 2021;16(1):1-0.

9. Capogna BM, Egol KA. Treatment of nonunions after malleolar fractures. Foot and ankle clinics 2016;21(1):4962.

10. Herscovici D, Scaduto JM, Infante A. Conservative treatment of isolated fractures of the medial malleolus. J Bone Joint Surg Br 2007;89(1):89-93.

11. Aitken SA, Johnston I, Jennings AC, Chua IT, Buckley RE. An evaluation of the Herscovici classification for fractures of the medial malleolus. Foot and Ankle Surgery 2017;23(4):317-20.

12. Tanna DD, Kumar P, Dhillon MS. Nonunion of Medial Malleolus Fracture: Tension Band Wiring is an Effective Option Even in Failed Surgeries. Journal of Foot and Ankle Surgery (Asia Pacific) 2019;6(2):53.

13. Bulut T, Gursoy M. Isolated medial malleolus fractures: conventional techniques versus headless compression screw fixation. The Journal of Foot and Ankle Surgery. 2018;57(3):552-6.

14. Fowler TT, Pugh KJ, Litsky AS, Taylor BC, French BG. Medial malleolar fractures: a biomechanical study of fixation techniques. Orthopedics 2011;34(8):e349-55.

15. Nauth A, Giannoudis PV, Einhorn TA et al. Growth factors: beyond bone morphogenetic proteins. J Orthop Trauma 2010;24:543-546.

16. Stewart SK. Fracture non-union: a review of clinical challenges and future research needs. Malaysian orthopaedic journal 2019;13(2):1.

17. Çabuk H, İmren Y, Dedeoğlu SS, Kır MÇ, Gürbüz S, Gürbüz H. The epiphyseal scar joint line distance and age are important factors in determining the optimal screw length for medial malleoli fractures. Injury 2019;50(4):1000-3.

18. Hanhisuanto S, Kortekangas T, Pakarinen H, Flinkkilä T, Leskelä HV. The functional outcome and quality of life after treatment of isolated medial malleolar fractures. Foot and Ankle Surgery 2017;23(4):225-9.

19. Ricci WM, Tornetta P, Borrelli Jr J. Lag screw fixation of medial malleolar fractures: a biomechanical, radiographic, and clinical comparison of unicortical partially threaded lag screws and bicortical fully threaded lag screws. Journal of orthopaedic trauma 2012;26(10):602-6.

20. Richmond J, Colleran K, Borens O, Kloen P, Helfet DL. Nonunions of the distal tibia treated by reamed intramedullary nailing. Journal of orthopaedic trauma. 2004;18(9):603-10.
21. Porter DA, May BD, Berney T. Functional outcome after operative treatment for ankle fractures in young athletes: a retrospective case series. Foot Ankle Int 2008;29:887894

22. Bhan K, Patel R, Hasan K, Pimplé M, Sharma S, Nandwana V, Basta M. Fracture Nonunions and Delayed Unions Treated With Low-Intensity Pulsed Ultrasound Therapy: A Clinical Series. Cureus 2021;13(8).

23. Mendelsohn HA. Nonunion of malleolar fractures of the ankle. Clin Orthop Relat Res 1965;42:103-118.

24. Banks SW. The treatment of non-union of fractures of the medial malleolus. J Bone Joint Surg Am 1949;31A(3):658-662.

25. Anderson SA, Li X, Franklin P, Wixted JJ. Ankle fractures in the elderly: initial and long-term outcomes. Foot Ankle Int. 2008;29:1184-1188.

26. Shur V, Georgiev K. Stabilization Technique for Comminuted Medial Malleolus Fractures. Techniques in Orthopaedics 2015;30(4):259-61.

27. Carter TH, Oliver WM, Graham C, Duckworth AD, White TO. Medial malleolus: Operative Or Nonoperative (MOON) trial protocol-a prospective randomised controlled trial of operative versus nonoperative management of associated medial malleolus fractures in unstable fractures of the ankle. Trials. 2019;20(1):1-9.

28. Lareau CR, Bariteau JT, Paller DJ, Koruprolu SC, DiGiovanni CW. Contribution of the medial malleolus to tibiotalar joint contact characteristics. Foot \& ankle specialist 2015;8(1):23-8. 